\title{
Temporal trend of cardiorespiratory endurance in urban Catalan high school students over a 20 year period
}

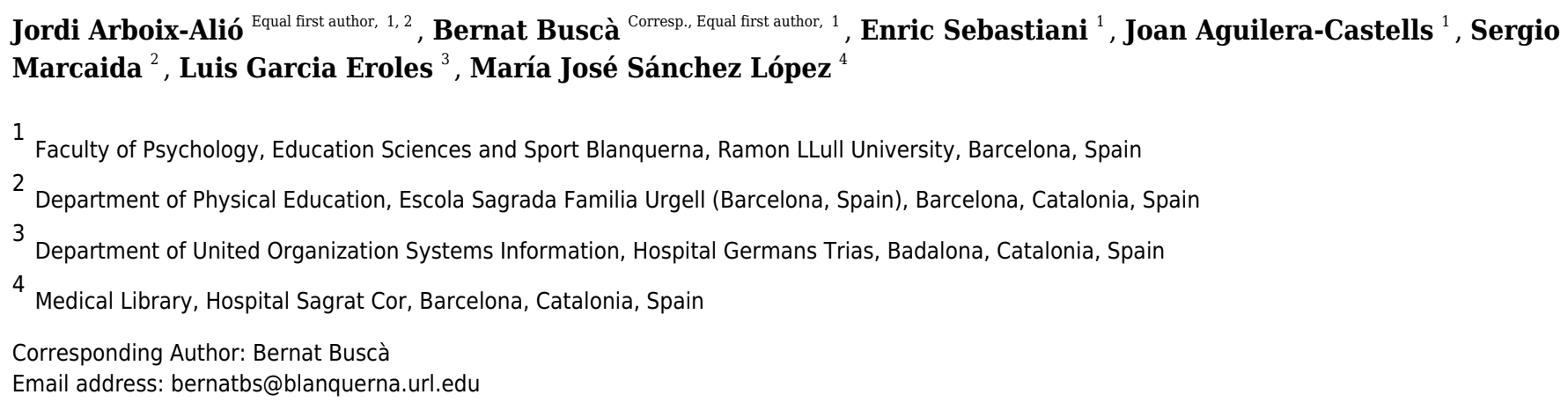

Background. Physical fitness is considered an important indicator of health in adolescents. However, in recent years several studies in the scientific literature have shown a considerable lower trend and an alarming worsening of the current adolescents' physical condition when comparing with previous decades, especially in urban populations. The aim of the current study was to analyse the temporal trend in cardiorespiratory endurance (CRE) in urban Catalan adolescents over a 20-year period (1999-2019). Methods. A cross-sectional analysis study considering the 20-m Shuttle Run test results obtained in the last 20 years was carried out. 1,701 adolescents between 15 and 16 years old (914 boys and 787 girls) were divided into four groups, corresponding to consecutive periods of five years (Group 1: 1999-2004; Group 2: 2005-2009; Group 3: 2010-2014 and Group 4: 2015-2019). ANOVA was used to test the period effect on CRE and pos hoc Bonferroni analysis was performed to test pairwise differences between groups ( $p<0.05$ ). Results. Results showed a significantly lower performance in CRE in both sexes. The percentual negative difference was $0.67 \%, 9.6 \%$ and $7 \%$ for boys, and $5.06 \%, 14.97 \%$ and 9.41\% for girls, when comparing the performance in 20-m Shuttle Run test respect the first period respectively. Conclusions. Results suggest that the physical fitness of Catalan urban adolescents is lower in both sexes when comparing the different analysed periods of time. Therefore, CRE adolescents should be improved in order to help to protect against cardiovascular disease and other health risks in adulthood. 


\section{Temporal trend of cardiorespiratory endurance in}

2 urban Catalan high school students over a 20 year 3 period

4

5

6

7

8

9

10

11

22

23

24

25

26

27

28

29

30

31

32

33

34

35

36

37

38

Arboix-Alió, Jordi. ${ }^{1}{ }^{2}$, Buscà, Bernat. ${ }^{1}$, Sebastiani, Enric. ${ }^{1}$, Aguilera-Castells, Joan. ${ }^{1}$, Marcaida, Sergio. ${ }^{2}$,García-Eroles, Luís. ${ }^{3}$, Sánchez-López, María-José. ${ }^{4}$

1: Faculty of Psychology, Education Sciences and Sport Blanquerna, Ramon Llull University (Barcelona, Spain).

2: Sagrada Familia school (SAFA), Physical Education Department (Barcelona, Spain).

3: Department of United Organization Systems Information, Hospital Germans Trias (Badalona, Spain).

4:Medical Library, Hospital Universitari Sagrat Cor (Barcelona, Spain).

Corresponding Author:

Bernat Buscà ${ }^{1}$

Cister Street 34, Barcelona, 08022, Spain

Email address: bernatbs@blanquerna.url.edu 
39

40

41

42

43

44

45

46

47

48

49

50

51

52

53

54

55

56

57

58

59

60

61

62

63

64

65

66

67

68

69

70

71

72

73

74

75

76

Background. Physical fitness is considered an important indicator of health in adolescents. However, in recent years several studies in the scientific literature have shown a considerable lower trend and an alarming worsening of the current adolescents' physical condition when comparing with previous decades, especially in urban populations. The aim of the current study was to analyse the temporal trend in cardiorespiratory endurance (CRE) in urban Catalan adolescents over a 20-year period (1999-2019).

Methods. A cross-sectional analysis study considering the 20-m Shuttle Run test results obtained in the last 20 years was carried out. 1,701 adolescents between 15 and 16 years old (914 boys and 787 girls) were divided into four groups, corresponding to consecutive periods of five years (Group 1: 1999-2004; Group 2: 2005-2009; Group 3: 2010-2014 and Group 4: 2015-2019). ANOVA was used to test the period effect on CRE and pos hoc Bonferroni analysis was performed to test pairwise differences between groups $(p<0.05)$.

Results. Results showed a significantly lower performance in CRE in both sexes. The percentual negative difference was $0.67 \%, 9.6 \%$ and $7 \%$ for boys, and $5.06 \%, 14.97 \%$ and $9.41 \%$ for girls, when comparing the performance in 20-m Shuttle Run test respect the first period respectively.

Conclusions. Results suggest that the physical fitness of Catalan urban adolescents is lower in both sexes when comparing the different analysed periods of time. Therefore, CRE adolescents should be improved in order to help to protect against cardiovascular disease and other health risks in adulthood.

3

4

5

6

7

8

9

70

71

72

73

74

75


77

\section{Introduction}

79

80

81

82

83

84

85

86

87

88

89

90

91

92

93

94

95

96

97

98

99

100

101

102

103

104

105

106

107

108

109

110

111

112

113

114

115

116 2008). et al., 2014).

Physical fitness is a set of physical and evaluable attributes related to the ability to perform physical exercise, and it also provides an important indicator of health (Tomkinson, Carver, et al., 2017). Physical fitness can be thought as an integrated measure of most body functions (skeletomuscular, cardiorespiratory, circulatory, psychoneurological and endocrine-metabolic) involved in the performance of the daily physical exercise (Ortega, Ruiz, Castillo, \& Sjöström,

Low physical exercise among children and adolescents has become a problem because its consequences constitute a risk factor for the health of general population. Moreover, this low physical exercise is closely related to different diseases such as obesity or diabetes (Héroux et al., 2013; Nechuta et al., 2015). These diseases are negatively impacting national health systems, not only in adults, but also in children and adolescents (García-Hermoso, Ramírez-Vélez \& Saavedra, 2019). Beside with low physical exercise (less than 60 minutes per day according to the World Health Organization (WHO) recommendations), the adolescents' intake of energydense diets and the sedentary lifestyle (sitting time, new technologies abuse or means of transport uses) contribute negatively in health and quality of life. In this vein, the PASOS (Physical Activity, Sedentarism and Obesity in Spanish Youth) study showed that only 36.7\% of children and adolescents fulfill with the WHO recommendations (Gómez et al., 2019). Also, this study showed that the percentage of inactivity was higher in girls respect to boys $(70.1 \%$ vs. $56.1 \%)$ and higher in adolescents respect to children (69.9\% vs. $56.1 \%)$. Thus epidemiologists have been suggested that physical fitness level may play a crucial role in treating overweight and obesity in this population (Watts et al., 2005).

One of the most important body functions is cardiorespiratory endurance (CRE), also known as cardiovascular fitness or aerobic fitness, which refers to the ability of the heart, lungs and circulatory system to supply oxygen to functioning muscles for prolonged periods of time (Armstrong, Tomkinson \& Ekelund, 2011; Tomkinson et al., 2017b). Therefore, the CRE physical condition is an important factor that reflects the health condition of the population (Castillo-Garzón et al., 2006; Gualteros et al., 2015). Concretely, significant associations have been found between CRE and obesity, diastolic and systolic blood pressure, cholesterol levels and cardiovascular health (Ortega et al. 2008). Moreover, a systematic physical exercise entails several health benefits for the active population, also affecting positively their self-esteem or social relationships (Héroux et al., 2013; Lang, Belanger, et al., 2018; Ortega et al., 2008; Smith

It is well supported that many adult chronic health diseases have their origin in childhood, especially in adolescence (Lang et al., 2018a). For instance, a recent longitudinal study found a significant association between a low cardiorespiratory fitness level, assessed with $20 \mathrm{~m}$-shuttle run test, and future cardiovascular disease in Spanish children aged 6 to 10-yearold. The children with higher cardiorespiratory fitness level were more likely to have a

PeerJ reviewing PDF | (2020:07:51255:1:0:NEW 7 Oct 2020) 
117 cardiovascular disease risk (boys odd ratio of 7.117 and 4.439 for girls) (Castro-Piñero et al. 118 2017). Other studies have demonstrated that both biological and behavioural risk factors 119 influences the health status in adulthood. Thus, CRE levels in adolescence are moderately to 120 strongly associated with CRE levels in adulthood, therefore enabling future health predictions 121 (Lang et al., 2018b). Moreover, adolescence is a crucial stage towards a healthy lifestyle because 122 puberty is a key period for skeletal mineralization and obesity prevention (Smith et al., 2014). In

123

124

125

126

127

128

129

130

131

132

133

134

135

136

137

138

139

140

141

142

143

144

145

146

147

148

149

150

151

152

153

154

155

156 addition, recent studies have shown an increasing trend of adolescents towards a sedentary lifestyle, considering it as the disease of the $21^{\text {st }}$ century (Mendoza-Muñoz et al., 2020), and suggesting that the recommended levels of physical exercise are not achieved (García-Hermoso, Ramírez-Vélez \& Saavedra, 2019).

The comparison of current adolescent physical fitness levels with those of previous decades clearly highlights the foreseen trends (Tomkinson et al., 2003; Westerstahl et al., 2003; Suris et al., 2006; Tomkinson \& Olds, 2007; Ferrari, Matsudo \& Fisberg, 2015). In this context, Tomkinson and Olds (2007) reported a decline of aerobic fitness average of $3.6 \%$ per decade in 25.4 million individuals aged 6-19 years from 27 countries between 1958 and 2003. Likewise, Tomkinson et al. (2003) analyzed the $20 \mathrm{~m}$ shuttle run test results of 129,882 children and adolescents aged 6-19 years from 11 countries indicating a decline of 4.3\% per decade between 1981 and 2000. Although the vast majority of trend studies show a similar behaviour of CRE among adolescents, Olds et al. (2006) have shown different slopes according to geographic area, thus suggesting the importance of researches in specific local populations. Indeed, the evolution of CRE in a concrete region or population is crucial to understand the impact of the nutritional, social or healthy habits, together with their physical condition.

In Spain, the data of the AVENA (Nutrition and Assessment of Nutritional Status of Spanish Adolescents) study noted that Spanish adolescents had worse physical condition than other countries (Ortega et al. 2005; Moliner-urdiales et al. 2010; Moreno et al. 2006). However, to the best of our knowledge, there is a paucity of studies analyzing the trends of CRE in Spanish and Catalan adolescents. Therefore, the aim of the present study was to analyse the temporal trend of CRE in a sample of urban Catalan adolescents over a 20-year period (1999-2019). It was hypothesized that adolescent population would show lower performance in the CRE test over the analysed time periods.

\section{Materials \& Methods}

\section{Design}

This is a cross-sectional study examining the temporal CRE trend of adolescents in the last 20 years. 1,701 adolescents (914 boys and 787 girls), aged 15 and 16 years, were evaluated in 20-m Shuttle Run Test. Tests were conducted by physical education teachers as part of several schools' physical education programs from 1999 to 2019 in Barcelona. A sample size of 1,529 
157

158

159

160

161

162

163

164

165

166

167

168

169

170

171

172

173

174

175

176

177

178

179

180

181

182

183

184

185

186

187

188

189

190

191

192

193

194

195

subjects was estimated by using EpiData 3.1 software (EpiData Association, Odense, Denmark), considering a confidence level of $95 \%$, and $2.5 \%$ accuracy. Because we intended to maintain that accuracy in both sexes, the minimum sample size was estimated in 1,635 students. Sample was selected through a suitable sampling group from several schools in Barcelona metropolitan area. According to the criterion of home proximity that governs the admission process of students in schools, their socio-economic level was generally considered medium-high. The inclusion criteria were age between 15 and 16 years old and attend school regularly ( $>80 \%$ attendance). Students who had a health problem that could bias any result or prevent you from taking a test of the study and students with high absenteeism ( $\geq 20 \%$ absences) were excluded from the study. No anthropometric data was considered due to the lack of uniformity in the data and the disparity of measurement instruments.

To compare the results over time, the sample has been disaggregated by sex and divided into four groups, corresponding to consecutive periods of five years. Thus, Group $1(\mathrm{n}=450)$ included the 1999-2004 classes; Group $2(\mathrm{n}=453)$, the 2005-2009; Group $3(\mathrm{n}=406)$, the 20102014 , and Group $4(\mathrm{n}=392)$ the 2015-2019. The distribution of the four-time periods was made arbitrarily in order to have a similar number of subjects in each period to facilitate comparisons.

All protocols conducted in this research complied with the requirements specified in the Declaration of Helsinki (revised in Fortaleza, Brazil, 2013) and all the participants signed informed consents after receiving a clear explanation. The Clinical Research Ethics Committee of Sagrat Cor Hospital (Barcelona, Spain) approved this study with reference number L-GENZ-E 004.

\section{Cardiorespiratory Endurance (CRE) test}

CRE was assessed using the $20-\mathrm{m}$ Shuttle Run (20m SRT). The $20 \mathrm{mSRT}$ is a running test used to estimate an athlete's aerobic capacity $\left(\mathrm{VO}_{2} \max \right)$. It consists of one-minute stages of continuous, incremental running speed. The initial speed is $8.5 \mathrm{~km} / \mathrm{h}$, and increases by $0.5 \mathrm{~km} / \mathrm{h}$ per minute (Léger et al., 1988). The participant is required to run between two lines 20-m apart while keeping the pace with a timed beep. The test ends when the individual fails in maintaining the pace (Lang et al., 2018a). The 20mSRT is simple, easy to administer, and is part of the ALPHA fitness test battery for children and adolescents (Castro-Piñero et al., 2010; Ruiz et al., 2011). Moreover, the test demonstrates strong test-retest reliability and moderate to strong validity, being considered the best and most popular field-based measurement of CRE among youth (Mayorga-Vega, Aguilar-Soto \& Viciana, 2015).

\section{Statistical analysis}


196 Statistical analyses were performed using SPSS (Version 20 for Windows; SPSS Inc.,Chicago, 197 IL, USA). The Kolmogorov-Smirnov test was used to check the normality of the data. 198 Descriptive statistics were used to describe the general demographic and practice characteristics 199 of the sample population: means, SDs, and range for continuous variables, and absolute and 200 relative frequencies for categorical variables. The differences in physical fitness (dependent 201 variable) among the groups (independent variable) were tested using one-way-ANOVA. 202 Bonferroni post-hoc tests were used to observe the pairwise differences between groups. The 203 significance level was set at $\mathrm{p}<0.05$ for all statistical analyses. Moreover, effects sizes were 204

205

206

207

208

209

210

211

212

213

214

215

216

217

218

219

220

221

222

223

224

225

226

227

228

229

230

231

232

233

234

235 reported as partial eta-squared $\left(\eta_{\mathrm{p}}{ }^{2}\right)$, with cut-off values of $0.01-0.05,0.06-0.13$, and $>0.14$ for small, medium, and large effects, respectively (Cohen, 1988). For pairwise comparison, the Cohen's $d$ effect size was calculated (Cohen, 1988), and the magnitude of the effect size was interpreted as $<0.2=$ trivial; $0.2-0.6=$ small; $0.6-1.2=$ moderate; $1.2-2.0=$ large; $>2.0=$ very large (Hopkins et al., 2009).

\section{Results}

Results showed a significantly lower cardiorespiratory endurance performance in both sexes when comparing the different temporal groups $(p<0.05)$. Boys groups showed a lower performance in the CRE physical capacity, which was significant from the period 2005-2009 onwards $\left[F_{(3,911)}=13.67 \mathrm{p}=0.000, \eta_{\mathrm{p}}{ }^{2}=0.043\right]$. Group 1 (1999-2004) reported higher performance (10.48 \pm 2.18$)$ as compared to the Group 3 (2010-2014) and to the Group 4 (20152019) $(9.42 \pm 2.11, \mathrm{p}=0.000, \mathrm{~d}=0.49 ; 9.61 \pm 1.88, \mathrm{p}=0.001, \mathrm{~d}=0.43$; respectively). Similarly, Group 2 (2005-2009) also reported a higher performance (10.35 \pm 2.27 ) compared to 2010-2014 and 2015-2019 groups $(9.42 \pm 2.11, \mathrm{p}=0.001, \mathrm{~d}=0.42 ; 9.69 \pm 1.98, \mathrm{p}=0.046, \mathrm{~d}=0.36$; respectively), showing lower CRE. Additionally, Group 4 (2015-2019) showed a non-significant upward trend in comparison with the group 3. Table 1 and Figure 1 summarize the results of the $20 \mathrm{mSRT}$ for each group for both sexes.

The girls trend showed a similar pattern. There was a significantly lower CRE over time $\left[F_{(3,784)}=11.76 \mathrm{p}=0.000, \eta_{\mathrm{p}}{ }^{2}=0.043\right]$, and an upward trend, although non-significant, in the 2015-2019 group respect the 2010-2014. Furthermore, girls reported the highest performance in the 1999-2004 group (6.91 \pm 1.72 stages), and showed a significantly lower CRE performance in the 2010-2014 and 2015-2019 groups $(5.91 \pm 1.66, \mathrm{p}=0.000, \mathrm{~d}=0.59 ; 6.18 \pm 1.67, \mathrm{p}=0.009, \mathrm{~d}$ $=0.43$; respectively).

**Table 1 about here**

The percentual comparison in boys was $0.67 \%, 9.6 \%$, and $7 \%$ chronologically lower respect the 1999-2004 group. On the other hand, girls showed a chronologically lower CRE performance of 5.06\%, 14.97\%, and 9.41\% respect the 1999-2004 group (Fig. 1). Figure 2 shows 
236 the temporal trend of the $20 \mathrm{~m}$ SRT results during each promotion since 1999. For the 20 years

237

238

239

240

241

242

243

244

245

246

247

248

249

250

251

252

253

254

255

256

257

258

259

260

261

262

263

264

265

266

267

268

269

270

271

272

273

274

275

analysed, CRE results both for boys and girls followed a similar trend.

**Figure 1 about here**

**Figure 2 about here**

\section{Discussion}

The present investigation aimed to analyse the temporal trend of CRE in a sample of Catalan adolescents over a 20-year period (1999-2019). The main finding of the study confirms a significantly lower performance of the most recent groups (3 and 4) compared to previous groups (1 and 2) in CRE, assessed with 20mSRT, in adolescents of both sexes in the last 20 years.

These results are in line with those previously reported, showing a general and progressive downward trend in adolescents' aerobic capacity compared to those of the previous decades (Arboix-Alió, Puigvert, Ramos, \& Sebastiani, 2014; Ferrari et al., 2015; Suris et al., 2006; Tomkinson et al., 2003; Westerstahl et al., 2003). Concretely, in the present study successive groups achieved a lower percentual CRE performance of $0.67 \%, 9.6 \%$, and $7 \%$ in boys and 5.06\%, 14.97\%, and 9.41\% in girls when compared with the first group (1999-2004). Similar to the findings of the present study, Tomkinson and Olds (2007) and Tomkinson et al. (2007) reported lower CRE performance around 4\% per decade in subjects aged 6-19 years of different countries. In Spain, the data of the AVENA Study (Nutrition and Assessment of Nutritional Status of Spanish Adolescents) reported that adolescents had worse physical condition respect other countries, and estimated that one out of five adolescents were at risk for future cardiovascular events in adulthood (Ortega et al. 2005). Apart from the physiological benefits of physical exercise ( $\mathrm{Wu}$ et al., 2019), it has also been reported its benefits on mental health (Asare, 2015), bone health (Bland et al., 2020) or cognitive abilities, and how it can help children in the learning processes. Indeed, an improvement of aerobic capacity increases monoamines (dopamine, epinephrine, and norepinephrine), resulting in short- and long-term changes in the structure and functioning of brain regions that are responsible of learning (Best, 2010), promotes angiogenesis and neurogenesis in the hippocampus, which is the part of the brain responsible of memory (Hassevoort et al., 2016), and has the potential to induce vascularization and neural growth of some brain regions (Donnelly et al., 2016; Esteban-Cornejo et al., 2017). Additionally, from a psychological and sociological perspective, schoolchildren with higher aerobic capacity tend to be physically more active, present less sedentary behaviour patterns and spend their free time in activities with greater cognitive involvement (RosaGuillamón et al., 2019).

Despite not having a single factor explaining the trend of lower performance in CRE reported in the present study, it could be speculated that is probably caused by the combination of environmental, social, behavioural, physical, psychosocial and physiological factors (Garland

Peer] reviewing PDF | (2020:07:51255:1:0:NEW 7 Oct 2020) 
276 et al., 2011; Ramos, Jiménez-Iglesias, Rivera, \& Moreno, 2016; Tomkinson \& Olds, 2007). In 277 this vein, physiological changes are affected by physical changes, such as the increase of fat, 278 directly connected with CRE achievements (Tomkinson et al., 2017b). It is well reported that 279 additional fat tissue increases the energy expenditure and the oxygen's cost of running. 280 Therefore, this fact would reduce running performance for any given absolute aerobic power 281 value (Cureton et al., 1978). Indeed, in many countries, the changes in fatness have coincided 282 with changes in CRE performance (Dollman et al., 1999; Tomkinson et al., 2012). Consequently, 283 obesity has become a major public health concern and a significant threat to health. The 284 prevalence of overweight and obesity among children and adolescents has increased in all 285 countries and has already reached alarming levels, especially in industrialized countries (Kosti \& 286 Panagiotakos, 2006). For instance, Spain is one of the countries with the highest incidence of

287

288

289

290

291

292

293

294

295

296

297

298

299

300

301

302

303

304

305

306

307

308

309

310

311

312

313

314 overweight and obesity in the world (Wijnhoven et al., 2014). The Spanish National Health Survey (SNHS), reporting data of children and adolescents aged between 2 and 17 years, determined that the percentage of overweight (body mass index) and obesity in Spain was 28.6\% (Mendoza-Muñoz et al., 2020). For this reason, it has become one of the greatest challenges for public health in the 21 st century because it represents a high cost for the healthcare system (Ortega, Ruiz, \& Castillo 2013). The health consequences of being obese include physiological disorders; such as dyslipidemia, diabetes, and uterine, colon, breast and prostate cancer; as well as to psychological and social disorders. Low self-esteem, feelings of inferiority, lack of control over impulses, depression, antisocial attitudes or inactivity are connected with children and adolescents with overweight (Bastos et al., 2005).

Recent research has linked these changes in body composition to eating and physical exercise patterns. The current trend of having prepared and processed foods easily accessible and in larger portion sizes, together with insufficient levels of physical exercise, are closely associated with social and economic problems (Ortega et al. 2008). Although Bastos et al. (2005) pointed out that there is no one single factor inducing the development of obesity (genetics, nutrition, psychology, social, and physical inactivity), showed the inactivity as the most relevant, considering that physical exercise plays a vital role in maintaining a healthy lifestyle. The present study analysed the CRE trend of urban population of med-high socioeconomic level. This population is generally involved in physical exercise in the school and/or family contexts. For this reason, one can reasonably think that adolescents with lower socioeconomic levels and worse physical exercise engagement, might present a worse downward CRE pattern in these periods (Serral-Cano et al., 2019). Concerning the CRE performance, Artero et al. (2009) suggested that overweight and obese adolescents achieve lower performances compared with their normal-weight counterparts in all tests requiring propulsion or lifting of the body mass like the $20 \mathrm{mSRT}$, while Tomkinson \& Olds (2017) reported a stronger negative relationship between fat mass and distance running. Therefore, it seems reasonable to think that an increase in overweight in adolescent population could be closely related to fitness decrease, and thus lower CRE as reported in the present study. 
Another reason connected with physical inactivity, and therefore explaining the lower CRE performance trend showed in the present study, is the use of new technologies. An inappropriate or abusive use can have important negative consequences for children and adolescents. Nowadays, new technologies (social networks, internet, smartphones, video games, and television) have become popular hobbies for children and adolescents. However, these sedentary behaviours detract from more physically active leisure time pursuits. According to data from the Spanish National Institute of Statistics, 91.8\% of children between 10 and 15 years old are regular Internet users. Likewise, estimations from different studies suggest that a large number of young people in developed countries spend more than 4 hours per day watching TV, twice the recommended maximum time (Lavielle-Sotomayor et al., 2014). A study from the Pfizer Foundation (2009), reported that $98 \%$ of Spanish people aged 11 to 20 are online platform users, and $70 \%$ of them access to the Internet more than 1.5 hours per day. Results of the present study showed a remarkable low CRE performance for girls, but not for boys, in the last two years analysed (Figure 2). The irruption of social networks (Instagram, Tik Tok or Snapchat) among female adolescents in the last years is a social phenomenon that have changed her lifestyle and, therefore impacting their CRE.

Despite not being statistically significant, it should be noted a reverse trend between the 2006-2007 and 2009-2010 promotions, with a slightly better performance in CRE for both sexes. This slight increase could be related to some local sports events, which could promote physical exercise between the citizens like the 2009 Davis Cup or the 2010 European Athletics Championship, both held in Barcelona. Unfortunately, temporal trends in these behaviours are not clear, because of the difficulty in obtaining accurate measurements and temporal differences in sampling and methodology (Ekelund, Tomkinson \& Armstrong, 2011). Sustained improvements may require changes to promote healthier habits and environments, especially in schools.

In future studies, it would be interesting to increase the sample size. Furthermore, weight, body mass index, nutritional status, or sedentary habits have not been examined; therefore, given the impact on the results of the fitness tests, it would be interesting to collect and analyze such data. Similarly, future studies should also consider different socioeconomic status of the sample for contextualizing the adolescents' trends in physical fitness. Moreover, differences in testing conditions like climate, practice, or running surfaces and measurement errors (eg, methodological drift and diurnal variation) could be considered as a limitation.

\section{Conclusions}

The present study reports a significantly lower CRE performance in a sample of urban Catalan adolescents aged between 15 and 16 years old, for both genders, over a 20-year period. Concretely, girls showed a remarkable downward trend in the last period analysed (2015-2019).

In light of the results obtained in the present study, as well as according to the WHO many adolescents do not reach the recommended demands of weekly physical exercise, school 
355 and community-based youth programs should increase efforts to promote physical exercise 356 among children and young people. Additionally, the findings of the present investigation are of 357 interest from a curricular point of view since the existence of CRE downward trend in 358 adolescents could be a strong reason to raise the status of Physical Education, which 359 traditionally, has been perceived by the educational community as a less important subject than 360 other more traditional areas of the curriculum. 


\section{References}

362 Arboix-Alió J, Puigvert J, Ramos E, Sebastiani EM. 2014. Evolución de la condición física de los alumnos de la escuela maristas la inmaculada de barcelona en los últimos 15 años: un

364

365

366

367

368

369

370

371

372

373

374

375

376

377

378

379

380

381

382

383

384

385

386

387

388

389

390

391

392

393

394

395

396

397

398

399

400

401

402

403

404

405 estudio transversal. Revista Horizontes Pedagógicos 16:24-33.

Armstrong N, Tomkinson G, Ekelund U. 2011. Aerobic fitness and its relationship to sport, exercise training and habitual physical activity during youth. British journal of sports medicine 45:849-58. DOI: 10.1136/bjsports-2011-090200.

Artero EG, España-Romero V, Ortega FB, Jiménez-Pavón D, Ruiz JR, Vicente-Rodríguez G, Bueno M, Marcos A, Gómez-Martínez S, Urzanqui A, González-Gross M, Moreno LA, Gutiérrez A, Castillo MJ. 2009. Health-related fitness in adolescents: underweight, and not only overweight, as an influencing factor. The AVENA study. Scandinavian Journal of Medicine \& Science in Sports 20:418-427. DOI: 10.1111/j.1600-0838.2009.00959.x.

Asare, M. (2015). Sedentary Behaviour and Mental Health in Children and Adolescents: A Metaanalysis. Journal of Child and Adolescent Behaviour, 03(06). doi:10.4172/23754494.1000259

Bastos A, González Boto R, Molinero González O, Salguero del Valle A. 2005. Obesidad, nutrición y actividad física. Revista Internacional de Medicina y Ciencias de la Actividad Física y el Deporte 5:140-153.

Best, J. R. (2010). Effects of physical activity on children's executive function: Contributions of experimental research on aerobic exercise. Developmental Review, 30(4), 331-351. doi:10.1016/j.dr.2010.08.001

Bland, V. L., Heatherington-Rauth, M., Howe, C., Going, S. B., \& Bea, J. W. (2020). Association of objectively measured physical activity and bone health in children and adolescents: a systematic review and narrative synthesis. Osteoporosis International. doi:10.1007/s00198-020-05485-y

Castillo-Garzón MJ, Ruiz JR, Ortega FB, Gutierrez-Sainz A. 2006. A Mediterranean diet is not enough for health: Physical fitness is an important additional contributor to health for the adults of tomorrow. In: More on Mediterranean Diets. Basel: KARGER, 114-138. DOI: 10.1159/000097913.

Castro-Piñero J, Artero EG, Espana-Romero V, Ortega FB, Sjostrom M, Suni J, Ruiz JR. 2010. Criterion-related validity of field-based fitness tests in youth: a systematic review. British Journal of Sports Medicine 44:934-943. DOI: 10.1136/bjsm.2009.058321.

Castro-Piñero J, Perez-Bey A, Segura-Jiménez V, Aparicio VA, Gómez-Martínez S, IzquierdoGomez R, Marcos A, Ruiz JR. 2017. Cardiorespiratory fitness cutoff points for early detection of present and future cardiovascular risk in children. Mayo Clinic Proceedings 92:1753-1762. DOI: 10.1016/j.mayocp.2017.09.003. 
407

408

409

410

411

412

413

414

415

416

417

418

419

420

421

422

423

424

425

426

427

428

429

430

431

432

433

434

435

436

437

438

439

440

441

442

443

444

445

446

447

448

449

450

451

452

Cohen J. 1988. Statistical power analysis for behavioural science. Hilldale: Lawrence Erlbaum.

Cureton KJ, Sparling PB, Evans BW, Johnson SM, Kong UD, Purvis JW. 1978. Effect of experimental alterations in excess weight on aerobic capacity and distance running performance. Medicine and science in sports 10:194-9.

Dollman J, Olds T, Norton K, Stuart D. 1999. The Evolution of fitness and fatness in 10-11year-old australian schoolchildren: changes in distributional characteristics between 1985 and 1997. Pediatric Exercise Science 11:108-121. DOI: 10.1123/pes.11.2.108.

Donnelly, J. E., Hillman, C. H., Castelli, D., Etnier, J. L., Lee, S., Tomporowski, P., Lambourne, K., \& Szabo-Reed, A. N. (2016). Physical Activity, Fitness, Cognitive Function, and Academic Achievement in Children. Medicine \& Science in Sports \& Exercise, 48(6), 1197-1222. doi:10.1249/MSS.0000000000000901

Ekelund U, Tomkinson G, Armstrong N. 2011. What proportion of youth are physically active? Measurement issues, levels and recent time trends. British Journal of Sports Medicine 45:859-865. DOI: 10.1136/bjsports-2011-090190.

Esteban-Cornejo, I., Cadenas-Sanchez, C., Contreras-Rodriguez, O., Verdejo-Roman, J., MoraGonzalez, J., Migueles, J. H., Henriksson, P., Davis, C. L., Verdejo-Garcia, A., Catena, A., \& Ortega, F. B. (2017). A whole brain volumetric approach in overweight/obese children: Examining the association with different physical fitness components and academic performance. The ActiveBrains project. NeuroImage, 159, 346-354. doi:10.1016/j.neuroimage.2017.08.011

Ferrari GLDM, Matsudo VKR, Fisberg M. 2015. Changes in physical fitness and nutritional status of schoolchildren in a period of 30 years (1980-2010). Revista Paulista de Pediatria 33:415-422. DOI: 10.1016/j.rppede.2015.03.001.

García-Hermoso A, Ramírez-Vélez R, Saavedra JM. 2019. Exercise, health outcomes, and pædiatric obesity: A systematic review of meta-analyses. Journal of Science and Medicine in Sport 22:76-84. DOI: 10.1016/j.jsams.2018.07.006.

Garland T, Schutz H, Chappell MA, Keeney BK, Meek TH, Copes LE, Acosta W, Drenowatz C, Maciel RC, van Dijk G, Kotz CM, Eisenmann JC. 2011. The biological control of voluntary exercise, spontaneous physical activity and daily energy expenditure in relation to obesity: human and rodent perspectives. Journal of Experimental Biology 214:206-229. DOI: $10.1242 /$ jeb.048397.

Gómez S., Lorenzo L, Ribes C, Homs C. 2019. Informe Estudio PASOS 2019. Sant Boi de Llobregat: Barcelona, Spain.

Gualteros JA, Torres JA, Umbarila-Espinosa LM, Rodríguez-Valero FJ, Ramírez-Vélez R. 2015. Una menor condición física aeróbica se asocia con alteraciones del estado de salud en niños y adolescentes de Bogotá, Colombia. Endocrinologia y Nutricion 62:437-446. DOI: 
453

454

455

456

457

458

459

460

461

462

463

464

465

466

467

468

469

470

471

472

473

474

475

476

477

478

479

480

481

482

483

484

485

486

487

488

489

490

491

492

493

494

495

496

497

498

\subsection{6/j.endonu.2015.05.011.}

Hassevoort, K. M., Khan, N. A., Hillman, C. H., \& Cohen, N. J. (2016). Childhood Markers of Health Behavior Relate to Hippocampal Health, Memory, and Academic Performance. Mind, Brain, and Education, 10(3), 162-170. doi:10.1111/mbe.12108

Héroux M, Onywera V, Tremblay MS, Adamo KB, Lopez Taylor J, Jáuregui Ulloa E, Janssen I. 2013. The relation between aerobic fitness, muscular fitness, and obesity in children from three countries at different stages of the physical activity transition. ISRN Obesity 2013:110. DOI: $10.1155 / 2013 / 134835$.

Hopkins WG, Marshall SW, Batterham AM, Hanin J. 2009. Progressive statistics for studies in sports medicine and exercise science. Medicine \& Science in Sports \& Exercise 41:3-13. DOI: 10.1249/MSS.0b013e31818cb278.

Kosti RI, Panagiotakos DB. 2006. The epidemic of obesity in children and adolescents in the world. Central European journal of public health 14:151-9.

Lang JJ, Belanger K, Poitras V, Janssen I, Tomkinson GR, Tremblay MS. 2018a. Systematic review of the relationship between $20 \mathrm{~m}$ shuttle run performance and health indicators among children and youth. Journal of Science and Medicine in Sport 21:383-397. DOI: 10.1016/j.jsams.2017.08.002.

Lang JJ, Tremblay MS, Léger L, Olds T, Tomkinson GR. 2018b. International variability in 20 $\mathrm{m}$ shuttle run performance in children and youth: who are the fittest from a 50-country comparison? A systematic literature review with pooling of aggregate results. British journal of sports medicine 52:276. DOI: 10.1136/bjsports-2016-096224.

Lavielle-Sotomayor P, Pineda-Aquino V, Jáuregui-Jiménez O, Castillo-Trejo M. 2014. Actividad física y sedentarismo: Determinantes sociodemográficos, familiares y su impacto en la salud del adolescente. Revista de salud pública 16:161-172. DOI: 10.15446/rsap.v16n2.33329.

Léger LA, Mercier D, Gadoury C, Lambert J. 1988. The multistage 20 metre shuttle run test for aerobic fitness. Journal of Sports Sciences 6:93-101. DOI: 10.1080/02640418808729800.

Mayorga-Vega D, Aguilar-Soto P, Viciana J. 2015. Criterion-related validity of the 20-m shuttle run test for estimating cardiorespiratory fitness: A Meta-Analysis. Journal of sports science \& medicine 14:536-47.

Mendoza-Muñoz M, Adsuar JC, Pérez-Gómez J, Muñoz-Bermejo L, Garcia-Gordillo MÁ, Carlos-Vivas J. 2020. Well-being, obesity and motricity observatory in childhood and youth (WOMO): A study protocol. International Journal of Environmental Research and Public Health 17:1-15. DOI: 10.3390/ijerph17062129.

Moliner-urdiales D, Ruiz JR, Ortega FB, Jiménez-pavón D, Moreno LA, Groups HS. 2010. 
499

500

501

502

503

504

505

506

507

508

509

510

511

512

513

514

515

516

517

518

519

520

521

522

523

524

525

526

527

528

529

530

531

532

533

534

535

536

537

538

539

540

541

542

543

544

Secular trends in health-related physical fitness in Spanish adolescents : The AVENA and HELENA Studies. Journal of Science and Medicine in Sport 13:584-588. DOI: 10.1016/j.jsams.2010.03.004.

Moreno LA, Mesana MI, González-Gross M, Gil CM, Fleta J, Wärnberg J, Ruiz JR, Sarría A, Marcos A, Bueno M. 2006. Anthropometric body fat composition reference values in Spanish adolescents. The AVENA Study. European Journal of Clinical Nutrition 60:191196. DOI: $10.1038 /$ sj.ejen.1602285.

Nechuta SJ, Shu XO, Yang G, Cai H, Gao Y-T, Li H-L, Xiang Y-B, Zheng W. 2015. Adolescent exercise in association with mortality from all causes, cardiovascular disease, and cancer among middle-aged and older chinese women. Cancer Epidemiology Biomarkers \& Prevention 24:1270-1276. DOI: 10.1158/1055-9965.EPI-15-0253.

Olds T, Tomkinson G, Léger L, Cazorla G. 2006. Worldwide variation in the performance of children and adolescents: An analysis of 109 studies of the 20-m shuttle run test in 37 countries. Journal of Sports Sciences 24:1025-1038. DOI: 10.1080/02640410500432193.

Ortega FB, Ruiz JR, Castillo MJ. 2013. Actividad física, condición física y sobrepeso en niños y adolescentes: evidencia procedente de estudios epidemiológicos. Endocrinología y Nutrición 60:458-469. DOI: 10.1016/j.endonu.2012.10.006.

Ortega F, Ruiz JR, Castillo MJ, Moreno LA, González-Gross M, Wärnberg J, Gutiérrez Á. 2005a. Bajo nivel de forma física en los adolescentes españoles. Importancia para la salud cardiovascular futura (Estudio AVENA). Revista Española de Cardiología 58:898-909. DOI: $10.1157 / 13078126$.

Ortega FB, Ruiz JR, Castillo MJ, Moreno LA, González M. 2005b. Bajo nivel de forma física en los adolescentes españoles. Importancia para la salud cardiovascular futura (Estudio AVENA ). Revista Española de Cardiología 58:898-909.

Ortega FB, Ruiz JR, Castillo MJ, Sjöström M. 2008. Physical fitness in childhood and adolescence: a powerful marker of health. International Journal of Obesity 32:1-11. DOI: 10.1038/sj.ijo.0803774.

Ramos P, Jiménez-Iglesias A, Rivera F, Moreno C. 2016. Evolución de la práctica de la actividad física en los adolescentes españoles / physical activity trends in spanish adolescents. Revista Internacional de Medicina y Ciencias de la Actividad Física y del Deporte 62:335-353. DOI: 10.15366/rimcafd2016.62.010.

Rosa-Guillamón, A., Garcia-Canto, E., \& Carrillo López, P. J. (2019). Capacidad aeróbica y rendimiento académico en escolares de educación primaria. Retos. Nuevas Tendencias En Educación Física, Deporte y Recreación, 35.

Ruiz JR, Castro-Pinero J, Espana-Romero V, Artero EG, Ortega FB, Cuenca MM, JimenezPavon D, Chillon P, Girela-Rejon MJ, Mora J, Gutierrez A, Suni J, Sjostrom M, Castillo 
545

546

547

548

549

550

551

552

553

554

555

556

557

558

559

560

561

562

563

564

565

566

567

568

569

570

571

572

573

574

575

576

577

578

579

580

581

582

583

584

585

586

587

588

589

590

MJ. 2011. Field-based fitness assessment in young people: the ALPHA health-related fitness test battery for children and adolescents. British Journal of Sports Medicine 45:518524. DOI: $10.1136 / \mathrm{bjsm} .2010 .075341$.

Serral-Cano, G., Bru-Ciges, R., Sánchez-Martínez, F., \& Ariza-Cardenal, C. (2019). Overweight and childhood obesity according to socioeconomic variables in schoolchildren of third grade in the city of Barcelona. Nutrición Hospitalaria, 36(5), 1043-1048.

doi: $10.20960 /$ nh. 02205

Smith JJ, Eather N, Morgan PJ, Plotnikoff RC, Faigenbaum AD, Lubans DR. 2014. The health benefits of muscular fitness for children and adolescents: a systematic review and metaanalysis. Sports Medicine 44:1209-1223. DOI: 10.1007/s40279-014-0196-4.

Suris J-C, Michaud P-A, Chossis I, Jeannin A. 2006. Towards a sedentary society: trends in adolescent sport practice in switzerland (1993-2002). Journal of Adolescent Health 39:132134. DOI: $10.1016 /$ j.jadohealth.2005.09.001.

Tomkinson GR, Carver KD, Atkinson F, Daniell ND, Lewis LK, Fitzgerald JS, Lang JJ, Ortega FB. 2017a. European normative values for physical fitness in children and adolescents aged 9-17 years: results from 2779165 Eurofit performances representing 30 countries. British Journal of Sports Medicine:bjsports-2017-098253. DOI: 10.1136/bjsports-2017-098253.

Tomkinson GR, Lang JJ, Tremblay MS, Dale M, Leblanc AG, Belanger K, Ortega FB, Léger L. 2017b. International normative $20 \mathrm{~m}$ shuttle run values from 1142026 children and youth representing 50 countries. British Journal of Sports Medicine 51:1545-1554. DOI: 10.1136/bjsports-2016-095987.

Tomkinson GR, Léger L, Olds TS, Cazorla G. 2003. Secular trends in the performance of children and adolescents (1980-2000). An analysis of 55 studies of the $20 \mathrm{~m}$ shuttle run test in 11 countries. Sports Medicine 33:285-300.

Tomkinson GR, Macfarlane D, Noi S, Kim D-Y, Wang Z, Hong R. 2012. Temporal changes in long-distance running performance of Asian children between 1964 and 2009. Sports medicine (Auckland, N.Z.) 42:267-79. DOI: 10.2165/11599160-000000000-00000.

Tomkinson GR, Olds TS. 2007. Secular changes in pediatric aerobic fitness test performance: The global picture. In: Pediatric Fitness. Basel: KARGER, 46-66. DOI: 10.1159/000101075.

Watts K, Jones TW, Davis EA, Green D. 2005. Exercise Training in obese children and adolescents. Sports Medicine 35:375-392. DOI: 10.2165/00007256-200535050-00002.

Westerstahl M, Barnekow-Bergkvist M, Hedberg G, Jansson E. 2003. Secular trends in body dimensions and physical fitness among adolescents in Sweden from 1974 to 1995. Scandinavian Journal of Medicine and Science in Sports 13:128-137. DOI: 10.1034/j.16000838.2003.10274.x.

Peer) reviewing PDF | (2020:07:51255:1:0:NEW 7 Oct 2020) 
591 Wijnhoven TM, van Raaij JM, Spinelli A, Starc G, Hassapidou M, Spiroski I, Rutter H, Martos

592

593

594

595

596

597

598

599

600

601

602

603

604

605
É, Rito AI, Hovengen R, Pérez-Farinós N, Petrauskiene A, Eldin N, Braeckevelt L, Pudule I, Kunešová M, Breda J. 2014. WHO European childhood obesity surveillance initiative: body mass index and level of overweight among 6-9-year-old children from school year 2007/2008 to school year 2009/2010. BMC Public Health 14:806. DOI: 10.1186/14712458-14-806.

Wu, X. Y., Zhuang, L. H., Li, W., Guo, H. W., Zhang, J. H., Zhao, Y. K., Hu, J. W., Gao, Q. Q., Luo, S., Ohinmaa, A., \& Veugelers, P. J. (2019). The influence of diet quality and dietary behavior on health-related quality of life in the general population of children and adolescents: a systematic review and meta-analysis. Quality of Life Research, 28(8), 19892015. doi:10.1007/s11136-019-02162-4 


\section{Table 1 (on next page)}

Descriptive analysis of results in 20-m Shuttle Run test over a 20-year period. The data are shown as mean \pm SD.

*_Statistically different than Group 1

†_Statistically different than Group 2

§_Statistically different than Group 1

¥_Statistically different than Group 2 
1 Table 1. Descriptive analysis of results in 20-m Shuttle Run test over a 20 -year period. The data are

2 shown as mean $\pm \mathrm{SD}$.

\begin{tabular}{lcccc}
\hline & $\begin{array}{c}\text { Group 1: } \\
\mathbf{1 9 9 9 - 2 0 0 4} \\
(\mathbf{n}=\mathbf{4 5 0})\end{array}$ & $\begin{array}{c}\text { Group 2: } \\
\mathbf{2 0 0 5 - 2 0 0 9} \\
(\mathbf{n}=\mathbf{4 5 3})\end{array}$ & $\begin{array}{c}\text { Group 3: } \\
\mathbf{2 0 1 0 - 2 0 1 4} \\
(\mathbf{n}=\mathbf{4 0 6})\end{array}$ & $\begin{array}{c}\text { Group 4: } \\
\mathbf{2 0 1 5 - 2 0 1 9} \\
(\mathbf{n}=\mathbf{3 9 2})\end{array}$ \\
\hline Boys $(\mathrm{n}=914)$ & $10.42 \pm 2.18$ & $10.35 \pm 2.27$ & $9.42 \pm 2.11^{*} \dagger$ & $9.61 \pm 1.88^{*} \dagger$ \\
Girls $(\mathrm{n}=787)$ & $6.91 \pm 1.72$ & $6.56 \pm 1.85$ & $5.91 \pm 1.66 \S \ddagger$ & $6.18 \pm 1.67 \S$ \\
\hline
\end{tabular}

3 *_Statistically different than Group 1

4 †_Statistically different than Group 2

5 §_Statistically different than Group 1

6 +_Statistically different than Group 2

7 
Figure 1

Comparison of 20 meter Shutlle Run Test results between the groups. a) boys, b) girls.

a)

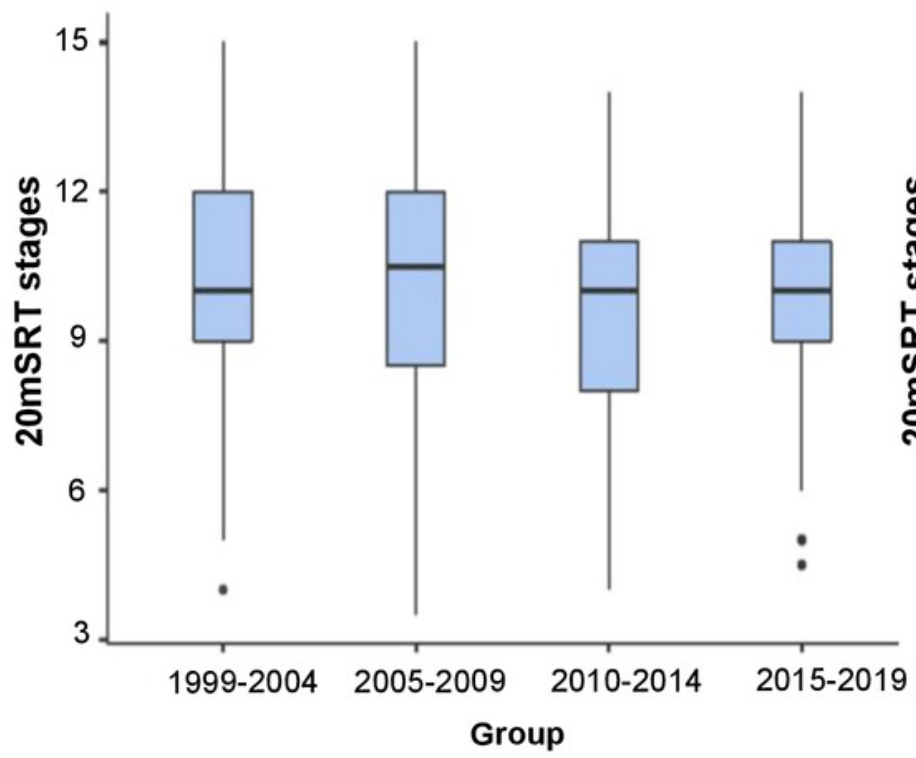

b)

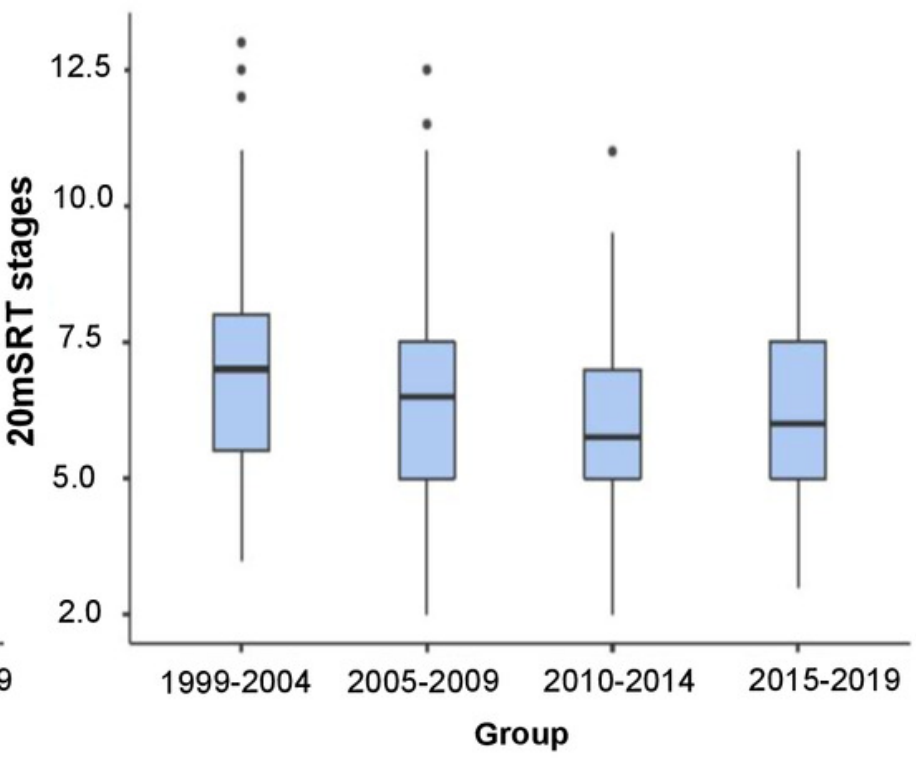


Figure 2

Evolution of 20 meter Shuttle Run Test results over the last 20 years.

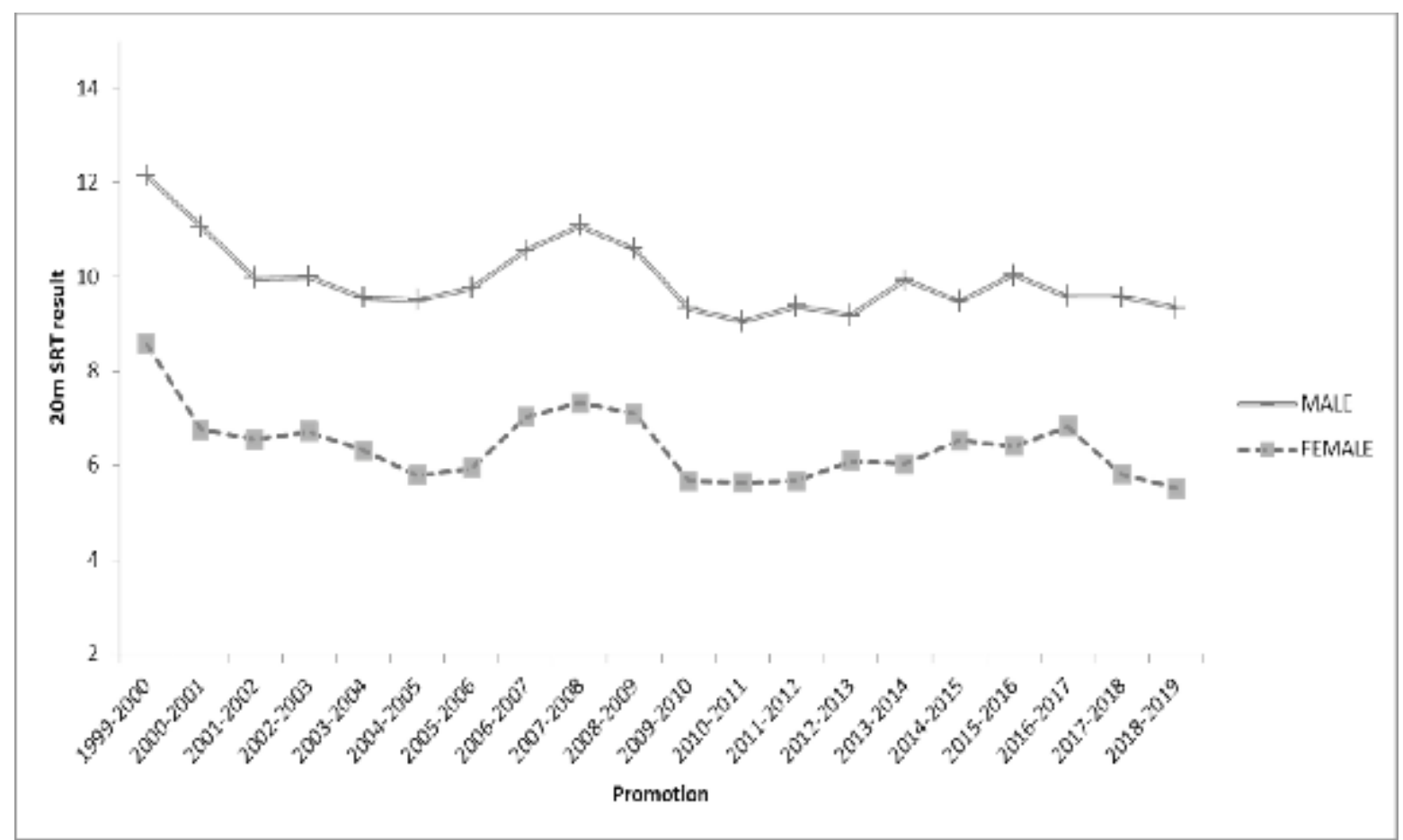

